\title{
Use of probiotics in dentistry
}

\author{
Pablo Alejandro Millones Gomez ${ }^{1,2 *}$ \\ ${ }^{1} \mathrm{PhD}$ Student, Universidad Peruana Cayetano Heredia, Lima, Perù \\ ${ }^{2}$ Researcher, Universidad Católica Santo Toribio de Mogrovejo. Chiclayo, Perù
}

\begin{abstract}
This review aims to describe the progress of the probiotic associated with its use in dentistry to treat various infections outside the oral cavity.

Infections of the oral cavity ranks sixth most common infections and are often one of the main causes of consultation in dentistry is why it has been treated most bacteria by mechanical procedures that sometimes must be accompanied by an irrational use of antibiotics which have been shown to be causing bacterial resistance and side effects or allergic reactions which is why we have opted promote a healthy environment in order to prevent the development of these infections through the use of multiple strategies, including the use of probiotics in order to achieve and maintain the ecological balance of the biofilm and the potential benefits of these they have already been studied in other areas of health.
\end{abstract}

\section{Introduction}

The oral cavity is an ecosystem in which a diverse microbiota is developed with about 700 species of bacteria living in a state of equilibrium, but with changes in diseases, behaviors, diet or medications, alter this homeostasis and allow bacteria to find The conditions necessary for its development, generating endogenous infections or susceptibility to exogenous infections, giving rise to oral infections that when they become chronic cause inflammatory processes releasing proinflammatory substances like cytokines, that manage to access any area of the organism through the circulatory system increasing the Risk of cardiovascular, muscular, digestive problems, premature birth, diabetes and sports injuries. For this reason, we have sought to eliminate most of the bacteria through mechanical procedures that sometimes have to be accompanied by antibiotics which have shown resistance, a number of adverse effects or allergic reactions. That is why there have been major changes in the treatment paradigm and has chosen to promote a healthy environment to prevent the development of these opportunistic infections through the use of multiple strategies. Now treatment options propose to alter the ecology of niches, in order to modify the pathological plaque to a biofilm of commensalism. Probiotics possess this property, managing to maintain the ecological balance of the biofilm since the potential benefits of these have already been studied in gastrointestinal and gynecological disorders [1-5].

Probiotics were first analyzed more than 100 years ago by the Nobel Prize Elías Metchnikkoff, who observed that the longevity of certain people in Bulgaria was higher because of the fermented milk they consumed, since they contained bacteria with probiotic properties, without However the term probiotics was first used by Lilly and Stilwell in 1965 to refer to substances secreted by a microorganism that stimulates the growth of another. In 2002, the Food and Agricultural Organization (FAO) and the World Health Organization (WHO) defined probiotics as products containing live microorganisms which, when administered in adequate amounts, exert a beneficial effect on human health or animal; In fact, a probiotic agent is a dietary formulation that contains an adequate number of living microorganisms, which provide nutrients and cofactors that have the ability to stimulate the immune response and repopulate beneficial bacteria, thus eliminating pathogenic bacteria by inhibiting their Growth or interacting with virulence factors of the latter eliminating the infection [4-7].

The relationship probiotics and oral cavity started from when the hypothesis of the plaque given by Marsh in 1994 was shared, who stated that oral infections are results of the changes that occurred in the balance of the microbiota that resides in the plaque, as a consequence of the modification of the local environmental conditions that allow the increase of pathogenic bacteria reaching such a number that predisposes the development of the disease; Based on the mentioned studies of oral probiotic potentials began to show results in the prevention of caries, also in the reduction of the number of oral candida or microflora associated with halitosis and in periodontal health; Most of these studies are carried out with the aim of obtaining a product of daily use, without side effects and that can be administered both in children and adults for optimum oral hygiene, for people who are going through moments of great stress and agitation, in Pregnant women or those who have an associated systemic disease $[1,2,8]$.

\section{Infections of the oral cavity}

These infections occupy the sixth place of the most common human infections; Is one of the main causes of consultation in dental practice, affecting at any stage of life, are also responsible for most of the prescriptions of antibiotics in the field of dentistry, presenting different degrees of severity and even some may be quite Complex and irreversible $[9,10]$.

Correspondence to: Pablo Alejandro Millones Gomez, PhD Student, Universidad Peruana Cayetano Heredia, Lima; Researcher, Universidad Católica Santo Toribio de Mogrovejo. Chiclayo, Perù, E-mail: pablomillones@gmail.com

Key words: probiotics, microbiota, dentistry

Received: August 01, 2017; Accepted: August 24, 2017; Published: August 26, 2017 


\section{Dental caries}

It was defined by the World Health Organization as a process of localized multifactorial origin, it constitutes a pathology with high prevalence in the population; Represents the highest percentage of dental morbidity and affects at any stage of life, gender and ethnicity, can affect the general health and quality of life of individuals; Among the main factors that determine its occurrence and distribution are the socioeconomic and educational level, the consumption of foods rich in sucrose between meals and the absence of hygienic habits [11].

\section{Periodontal disease}

They are infections that affect the tissues of dentin support, are characterized by the presence of more than 200 bacterial species, even evidence of its metastatic infestation, can reach different anatomical organs and thus cause pathological changes [12].

\section{Candidiasis}

It is the most frequent fungal infection in the oral cavity, generally caused by the type of Candida albicans, which is considered an opportunistic pathogen, which is why it is commonly called "sickness". It is prevalent on certain occasions as extreme ages (newborns and Elderly), in the presence of mucosal prostheses, xerostomia or in associated pathologies and in some pharmacological treatments [13].

\section{Probiotics and their role in oral cavity infections}

The oral cavity has recently been considered as a target for the application of probiotics because several studies carried out with the purpose of demonstrating the probiotic effectiveness of bacteria on infections belonging to the oral cavity have begun to show results in: Prevention of caries, reduction of the number of oral candida colonies, reduction of the microflora associated with halitosis, periodontal health and in different types of oral cancer. Probiotics have the ability of adhesion and integration within the biofilm structure. The ability to adhere to the surfaces where the saliva circulates and also manages to support the environmental conditions and defense mechanisms of the oral cavity allowing colonization and proliferation [1,2,6,14].

Yanine N, et al. [15] conducted a study aimed at evaluating the effects of probiotics in the prevention and / or treatment of periodontal diseases, obtained as results in small benefits Plaque Index and gingival inflammation making conclude That the efficacy of probiotics in the prevention and treatment of periodontal diseases is questionable.

Yunwo Zhu, et al. [16] assessed the competition between probiotics in the bio-yogurt and periodontal pathogens by agar diffusion assays using eight species of periodontal pathogens and bacteria as indicator strains and secondly isolating four probiotic yoghurt bacteria to evaluate competitive exclusion between both, obtained as a result that fresh yogurt inhibited all the six periodontal pathogens used in this study (Fusobacterium nucleatum, Porphyromonas circumdentaria, Prevotella nigrescens, A. actinomycetemcomitans, nigrescens and P. gingivalis) yogurt heat treated showed antimicrobial activity lower than the fresh yogurt due because the heat treated contains negligible viable microorganisms compared to fresh.

Baca, et al. [17] carried out a study with the purpose of comparing in vitro the activity of L. reuteri in pathogenic bacteria that participate in the formation of dental caries: S. mutans, S. gordonii and periodontal disease: A. naeslundii and T. forsythia. They obtained as a result that L. reuteri has an inhibitory effect against S. mutans, followed by $\mathrm{T}$. forsythia and S. gordonii, and is less significant against A. naeslundii;
Which led him to conclude that the use of L. reuteri may allow the prevention or treatment of oral diseases as it inhibits the growth of pathogenic bacteria.

Ince G [18] evaluated the complementary effects of L. reuteri on periodontal treatment in chronic periodontitis in clinical relation and biochemical parameters through the management of two groups. In the first group he administered L. reuteri pills with Scaling and root planing, and in another Scaling and root planing group with placebo, the result was a decrease in plaque index, bleeding at catheterization, and depth at catheterization, with a significantly greater effect in favor Of the test group in addition to a reduction in inflammation markers, concluding that tablets containing L. reuteri may be a useful adjunct in the moderately deep pockets of patients with chronic periodontitis succeeding in inhibiting the development of pathogenic bacteria of chronic periodontitis Which allows significant reductions in the matrix metalloproteinase- 8 inhibitor and the increase of metalloproteinases-1.

Szkaradkiewicz A, et al. [19] conducted a research whose objective was the evaluation of L. reuteri in the proinflammatory cytokine response in patients with chronic periodontitis, for which two groups were selected, one consisting of 24 patients and one of 14 patients Professional dental cleaning, with the variance in which the group of 24 were given a probiotic L. reuteri tablet; Resulting in a significant decrease in the levels of pro-inflammatory cytokines, in parallel detected an improvement of indices and the level of insertion, which concluded that the application of oral treatment of tablets with the probiotic strain of L. reuteri induce A significant reduction of pro-inflammatory cytokine response and improvement of clinical parameters because it suppresses the production of pro-inflammatory cytokines and prevents the colonization of pathogens.

Kang M, et al. [20] evaluated the effects of L. reuteri on the proliferation of periodontopathic bacteria including Actinobacillus Aggregatibacter, Fusobacterium, Porphyromonas gingivalis nucleatum and Tannerella forsythia, and on the formation of Streptococcus mutans biofilms in an in vitro study in the Which used human and rat derived L. reuteri strains; They obtained as a result that all strains of L. reuteri exhibited significant inhibitory effects on the growth of periodontopic bacteria and the formation of S. mutans biofilms due to the production of organic acids, hydrogen peroxide, and a bacteriocinlike compound And in addition to inhibiting the production of methyl mercaptan by F. nucleatum and P. gingivalis, they concluded that $\mathrm{L}$. reuteri may be useful as a probiotic agent to improve oral health.

Rebolledo M. and col. [21] evaluated the effect of probiotic strains Lactobacillus casei variety rhamnosus and Lactobacillus johnsonii on the in vitro growth of Streptococcus, the results showed that probiotics with strains Lactobacillus casei variety rhamnosus and Lactobacillus johnsonii inhibit growth on Streptococcus mutans; Both probiotics at the two highest concentrations did not show significant differences in relation to the inhibition halos, however, the probiotic with the strain Lactobacillus casei variety rhamnosus, showed more significant inhibition halos in comparison to the strain Lactobacillus johnsonii these results allowed them to conclude That the probiotic strains Lactobacillus casei variety rhamnosus and Lactobacillus Johnosonii reduce the colonization of the main bacteria producing dental caries, and could therefore be used as support in the prevention and prophylaxis of the disease in patients with high cariogenic risk, in addition to Other means of prevention.

Teanpaisan R, et al. [22] They evaluated the inhibitory effect of 10 oral Lactobacillus species in vitro against isolated oral pathogens 
obtained from 165 children with decayed teeth. As a result, the majority of oral Lactobacillus were able to inhibit the growth of pathogens associated with periodontitis and Caries but those who had stronger inhibitory activity was Lact. Paracasei, Lact. Plantarum, Lact. Rhamnosus, Lact. Casei and Lact. Salivarius. Lactobacillus SD1-SD6 therefore indicated that Lactobacillus may be of benefit as probiotics for the prevention of oral diseases since they inhibited the growth of both in vitro pathogens related to caries and periodontitis.

Kõll, et al. [23] Evaluated antimicrobial activity against putative oral pathogens, using a total of 10 species in an in vitro study; They found that the most prevalent strains in healthy people were Lactobacillus gasseri and Lactobacillus fermentum and in patients with chronic periodontitis, Lactobacillus plantarum. In addition, $69 \%$ of the lactobacilli tested inhibited S. mutans, $88 \%$ A. actinomycetemcomitans, $82 \%$ P. gingivalis and $65 \%$ P. intermedia. The strongest antimicrobial activity was associated with Lactobacillus paracasei, L. plantarum, Lactobacillus rhamnosus, Lactobacillus salivarius and. The strains of periodontally healthy patients showed a lower antimicrobial activity against $\mathrm{S}$. mutans than the strains of patients with chronic periodontitis based on what was said that they concluded that the composition of oral lactoflora in chronic periodontitis and healthy subjects is different, with a higher prevalence Of homofermentative lactobacilli, particularly L. gasseri, in the latter group. Both oral lactobacilli homo and heterofermentative suppress the growth of periodontal pathogens, but antimicrobial properties are stress, species and specific origin.

Nilssen L, et al. [24] made an in vitro study in order to see the effect of Lactobacillus salivarius and L. gasserien expression of the two major virulence factors of A. actinomycetemcomitans (leukotoxin and cytolethal distending toxin) obtaining as results lactobacilli did not affect the growth of these virulence factors, but strongly attenuates the expressions of both of which could indicate that lactobacilli can reduce the virulence of oral opportunistic pathogens themselves as these could reduce the ability of virulence of oral pathogens Due to an interaction that causes a kind of antagonism but which could also be subject to change due to food intake, diet and habits.

Mackawa T and Hajshengallis G [25] conducted a pilot study with mice whose purpose was to determine if CD2 Lactobacillus brevis could inhibit periodontal inflammation and bone loss in periodontitis. They found that mice treated topically with L. brevis CD2 significantly decreased bone loss and decreased tumor necrosis factor expression compared to placebo-treated mice; L. brevis also treated with CD2 mice show low counts of anaerobic bacteria, but higher counts of aerobic bacteria that mice treated with placebo so these data provide proof of concept that brevis CD2 L. prebiotic may inhibit periodontitis and That arginine deiminase can inhibit the production of nitric oxide which plays a role in periodontal inflammation and bone loss. K. Pangsomboon y col [26] en un estudio para mostrar purificación, identificación y caracterización parcial de bacteriocina producida por HL32 Lactobacillus paracasei contra Porphyromonas sp mediante un estudio in vitro obtuvo como resultado que la actividad antibacteriana es específica de bacteriocina contra Porphyromona sp. Lo cual les permitio concluir que bacteriocina tiene una actividad selectiva contra Porphyromonas sp. Por lo cual se le podría asociar con el tratamiento de enfermedad periodontal.

Flichy A [27] carried out an investigation whose purpose was to evaluate the effect of the oral probiotic Lactobacillus reuteri in edentulous patients with dental implants with mucositis divided into two groups patients with dental implants, one with mucositis and the other without peri-implant pathology, Both were given a probiotic L. reuteri tablet, the results obtained were that patients with mucositis and without peri-implant pathology showed improvements in clinical parameters, with reductions in cytokine levels and patients treated with placebo there was no difference Which allowed him to conclude that the administration of probiotics is a good alternative both for the treatment of peri-implant mucositis and for its prevention, improving even the clinical parameters in patients without periimplant pathology; In another study accompanied by Candel E, et al. [28] Evaluated treatment with the probiotic L. reuteri there are changes in the concentration of periodontopathogenic bacteria such as T. forsythia, P. gingivalis, T. denticola, A. actinomycetemcomitans, resulted in a significant decrease in T. forsythia, T. denticola and total bacterial load after administration of the probiotic; At the same time, they observed that in the implants the P. gingivalis, the Treponema denticola and the total bacterial load were significantly reduced, which allows them to conclude that after administration of oral probiotics there is an improvement in periodontal and peri-implant health as it reduces pathogenic bacterial load.

The evidence supports the clinical and in vitro effectiveness of the use of probiotics, both in treatment and prevention; However, further research is still needed to evaluate the mechanisms of action as well as the monitoring of their use over extended periods of time.

\section{References}

1. Muñoz K, y Alarcón M (2010) Efecto de los Probióticos en las Condiciones Periodontales. Rev Clin Periodoncia Implantol Rehabil Oral 1: 136-139.

2. Borghi R, Dutra Araujo T, Airoldi Vieira RI, Theodoro de Souza T, Waitzberg DL (2013) ILSI Task Force on enteral nutrition; estimated composition and costs of blenderized diets. Nutr Hosp 28: 2033-2038. [Crossref]

3. Allegra R, y Lynne C (2011) Probiotics for periodontal health: A review of the literature. $J$ Dent Hyg 86: 71-81. [Crossref]

4. Chatterjee A, Bhattacharya H, Kandwal A (2011) Probiotics in periodontal health and disease. J Indian Soc Periodontol 15: 23-28. [Crossref]

5. Gupta G (2011) Probiotics and periodontal health. J Med Life 4: 387-394. [Crossref]

6. Koduganti RR, Sandeep N, Guduguntla S, Chandana Gorthi VS (2011) Probiotics and prebiotics in periodontal therapy. Indian J Dent Res 22: 324-330. [Crossref]

7. Messora M, Oliveira L, Foureaux R, Taba M, Zangeronimo M, Furlaneto F, et al (2013) Probiotic therapy reduces periodontal tissue destruction and improves the intestinal morphology in rats with ligature-induced periodontitis. $J$ Periodontol 84: 1818-1826. [Crossref]

8. Losada M, Vicario M, Pujol A, Sanz J, y Nart J (2012) Probióticos: ¿Una opción de futuro? Varios Odontologia 22: 59-63.

9. Stamatova I, Meurman JH (2009) Probiotics and periodontal disease. Periodontol 2000 51: 141-151. [Crossref]

10. Velasco I, y Soto R (2012) Principios para el tratamiento de infecciones odontogénicas con distintos niveles de complejidad. Rev Chil Cir 64: 586-598.

11. Morón A, Navas R, Fox, Santana Y, y Quintero L (2009) Prevalencia de caries dental en las etnias venezolanas. Ciencia Odontológica 6.

12. Peña M, Calzado M, Gonzales M, Cordero S, y Azabares H (2012) Patógenos periodontales y sus relaciones con enfermedades sistémicas. MEDISAN 16.

13. Otero E, Peñamaría M, Rodríguez M, Marín B. y Blanco A (2015) Candidiasis oral en el paciente mayor Av Odontoestomatol.

14. Dhingra K (2012) Methodological issues in randomized trials assessing probiotics for periodontal treatment. J Periodontal Res 47: 15-26. [Crossref]

15. Yanine N, Araya I, Brignardello-Petersen R, Carrasco-Labra A, González A, et al (2013) Effects of probiotics in periodontal diseases: a systematic review. Clin Oral Investig 17: 1627-1634. [Crossref]

16. Yunwo Zhu, Liying Xiao, Da Shen y Yuqing Hao (2010) Competition between yogurt probiotics and periodontal pathogens in vitro. Acta Odontologica Scandinavica 68 : 261-268. 
17. Baca M, De la Garza M, Alcazar A, Grondin Y, Coronado A, et al. (2015) Antimicrobial effect of lactobacillus reuteri on cariogenic bacteria streptococcus gordonii, streptococcus mutans, and periodontal diseases actinomyces naeslundii and tannerella forsythia. Probiotics Antimicrob Proteins 7: 1-8. [Crossref]

18. İnce G, Gürsoy H, İp̧̧i ŞD, Cakar G, Emekli-Alturfan E, Yılmaz S (2015) Clinical and biochemical evaluation of lactobacillus reuteri containing lozenges as an adjunct to non-surgical periodontal therapy in chronic periodontitis. J Periodontol 86: 746-754. [Crossref]

19. Szkaradkiewicz AK, Stopa J, Karpiński TM (2014) Effect of oral administration involving a probiotic strain of Lactobacillus reuteri on pro-inflammatory cytokine response in patients with chronic periodontitis. Arch Immunol Ther Exp 62: 495-500. [Crossref]

20. Kang MS, Oh JS, Lee HC, Lim HS, Lee SW, et al. (2011) Inhibitory effect of Lactobacillus reuteri on periodontopathic and cariogenic bacteria. J Microbiol 49: 193199. [Crossref]

21. Rebolledo M; Rojas E, y Salgado F (2013) Efecto de Dos Probióticos que Contienen Cepas de Lactobacillus casei variedad rhamnosus y Lactobacillus johnsonii sobre el Crecimiento in Vitro de Streptococcus mutans. Int J Odontostomat 7: 415-419.

22. Teanpaisan R, Piwat S, Dahlén G (2011) Inhibitory effect of oral Lactobacillus against oral pathogens. Lett Appl Microbiol 53: 452-459. [Crossref]
23. Kõll-Klais P, Mändar R, Leibur E, Marcotte H, Hammarström L, Mikelsaar M (2005) Oral lactobacilli in chronic periodontitis and periodontal health: species composition and antimicrobial activity. Oral Microbiol Immunol 20: 354-361. [Crossref]

24. Nilssen L, Sgorbati B, Biavati B, Belibasakis G (2014) Lactobacillus salivarius and L. gasseri down-regulate Aggregatibacter actinomycetemcomitans exotoxins expression. Ann Microbiol 64: 611-617. [Crossref]

25. Mackawa T, Hajshengallis G (2014) Topical treatment with probiotic Lactobacillus brevis CD2 inhibits experimental periodontal inflammation and bone loss. J Periodont Res 49: 785- 791. [Crossref]

26. Pangsomboon K, Bansal S, Martin GP, Suntinanalert P, Kaewnopparat S, Srichana T (2009) Further characterization of a bacteriocin produced by Lactobacillus paracasei HL32. J Appl Microbiol 106: 1928-1940. [Crossref]

27. Flichy A (2013) Efecto del probiótico oral Lactobacillus reuteri Prodentis en la salud periimplantaria. Estudio clínico e inmunológico. Tesis Doctoral. Barcelona, España. Universidad de Valencia.

28. Flichy A, Candel E, Peñarrocha M (2013) Efecto de los probióticos orales en la microbiota periodontal y periimplantaria. Nutr Hosp 28

Copyright: $₫ 2017$ Gomez PAM. This is an open-access article distributed under the terms of the Creative Commons Attribution License, which permits unrestricted use, distribution, and reproduction in any medium, provided the original author and source are credited. 